\title{
BMJ Open Healthy lifestyle behaviour and risk of long-duration troublesome neck pain among men and women with occasional neck pain: results from the Stockholm public health cohort
}

\author{
Tony Bohman (D) , ${ }^{1}$ Lena W Holm, ${ }^{1}$ Johan Hallqvist, ${ }^{2}$ Oscar J Pico-Espinosa, ${ }^{1}$ \\ Eva Skillgate ${ }^{1,3,4}$
}

To cite: Bohman T, Holm LW, Hallqvist J, et al. Healthy lifestyle behaviour and risk of long-duration troublesome neck pain among men and women with occasional neck pain: results from the Stockholm public health cohort. BMJ Open 2019;9:e031078. doi:10.1136/ bmjopen-2019-031078

- Prepublication history and additional material for this paper are available online. To view these files, please visit the journal online (http://dx.doi. org/10.1136/bmjopen-2019031078).

Received 17 April 2019 Revised 30 August 2019 Accepted 28 October 2019

Check for updates

(c) Author(s) (or their employer(s)) 2019. Re-use permitted under CC BY-NC. No commercial re-use. See rights and permissions. Published by BMJ.

For numbered affiliations see end of article.

Correspondence to Dr Tony Bohman; tony.bohman@ki.se

\section{ABSTRACT}

Objectives The effect of a healthy lifestyle on the prognosis of neck pain is unknown. This study aimed to investigate if a healthy lifestyle behaviour influences the risk of long-duration troublesome neck pain among men and women with occasional neck pain.

Design Longitudinal cohort study.

Settings General population, and a subsample of the working population, in Stockholm County, Sweden.

Participants This study involved 5342 men and 7298 women, age 18 to 84, from the Stockholm Public Health Cohort, reporting occasional neck pain at baseline in 2006.

Measures Baseline information about leisure physical activity, smoking, alcohol consumption and consumption of fruits and vegetables were dichotomised into recommendations for healthy/not healthy behaviour. The exposure, a healthy lifestyle behaviour, was categorised into four levels according to the number of healthy behaviours $(\mathrm{HB})$ met. Generalised linear models were applied to assess the exposure on the outcome longduration troublesome neck pain (activity-limiting neck pain $\geq 2$ days/week during the past 6 months), at follow-up in 2010.

Results The adjusted risk of long-duration troublesome neck pain decreased with increasing adherence to a healthy lifestyle behaviour among both men and women (trend test: $p<0.05$ ). Compared with the reference category, none or one $\mathrm{HB}$, the risk decreased by $24 \%$ (risk ratio $0.76,95 \% \mathrm{Cl} 0.58$ to 0.98 ) among men and by $34 \%$ $(0.66,0.54$ to 0.81$)$ among women, with three or four HBs. The same comparison showed an absolute reduction of the outcome by $3 \%$ in men (risk difference $-0.03,95 \% \mathrm{Cl}$ -0.05 to -0.01$)$ and $5 \%$ in women $(-0.05,-0.08$ to -0.03$)$. Similar results were found in the working population subsample.

Conclusion Adhering to a healthy lifestyle behaviour decreased the risk of long-duration troublesome neck pain among men and women with occasional neck pain. The results add to previous research and supports the importance of promoting a healthy lifestyle behaviour.
Strengths and limitations of this study

- The longitudinal design, with the exposure measured prior the outcome, a large study population and the dose-response relation found for the associations are strengths in this study.

- The comprehensive confounder analyses strengthen the validity of the study even though residual confounding cannot be ruled out.

- Possible limitations in this study are the potential risk for misclassification of the exposure as all information was self-reported, and the fact that some of the questions used for collecting the data were not optimal in terms of validity and reliability. However, these limitations most likely resulted in an underestimation of the association studied.

- The relatively large loss to follow-up may also be considered as a limitation.

\section{INTRODUCTION}

According to an analysis of the Global Burden of Disease Study 2015, low back pain and neck pain were the leading causes of Years Lived with Disability (YLD) in 1990, 2005 and in 2015, with an increasing prevalence and incidence over the years. ${ }^{1}$ Hoy et al found neck pain alone to be the number four cause of YLDs globally, with a global point prevalence of $4.9 \%$, and with a higher prevalence among women. ${ }^{2}$ The prevalence of activity limiting neck pain is estimated to be $1.7 \%$ to $11.5 \%$ in the general population and $11 \%$ to $14.1 \%$ in workers. ${ }^{3}{ }^{4}$ Musculoskeletal disorders, including neck and low back pain, were the largest reason for initiated sick-leave spells among men, and the second largest reason among women in Sweden, in 2016. Even though the majority of neck pain problems have a favourable course, between $50 \%$ to $75 \%$ in the general population still report 
neck pain 1 to 5 years later. $^{6}$ Consequently, research is needed to increase the understanding of modifiable prognostic factors to facilitate management of neck pain, especially for factors that determine the transition from neck pain not limiting daily activity to activity limiting neck pain as this type of pain is the one constituting the largest burden on the society. ${ }^{27}$

A healthy lifestyle behaviour, assessed by a combination of several lifestyle factors, in relation to health have been studied since more than four decades. Already in 1970, Palmore found 'health practice', a combination of exercise, weight control and avoiding cigarettes, to decrease physicians visits, hospitalisation, operations and poor health rating in US community volunteers aged 60 to 90 years. ${ }^{8}$ Recently, Li et al found that adopting a healthy lifestyle behaviour, that is, not smoking, being regularly physically active, having 'normal' weight, moderate intake of alcohol and eating healthy food, to prolong life expectancy in the US population. ${ }^{9}$ Persons adhering to all five lifestyle factors could prolong life expectancy at 50 years up to 14 years, compared with persons not adhering to any of the lifestyle factors. Several other authors have found influence on risk and prognosis for outcomes such as diabetes, stroke, cancer, cardiovascular events and mortality when studying a healthy lifestyle behaviour as a combination of several lifestyle factors. ${ }^{10-13}$

The understanding of how a healthy lifestyle behaviour influences the risk and prognosis for musculoskeletal disorders is limited. Pronk et al discovered that adherence to four lifestyle factors; not smoking, low alcohol consumption, adequate physical activity and five servings of fruit and vegetables, decreased the risk of reporting chronic low back pain 2 years later in US employees. ${ }^{10}$ Our research group has previously focused on a healthy lifestyle behaviour, defined as following the healthenhancing recommendations for leisure time physically active, alcohol consumption, daily intake of fruit and vegetables and not smoking. We found that a healthy lifestyle behaviour reduces the risk of long-duration troublesome low back pain in men, and long-duration troublesome neck pain in women. ${ }^{14}$ We have also examined the influence of a healthy lifestyle behaviour in men and women with occasional low back pain, showing a decreased risk of long-duration troublesome low back pain in women, and indicating a decreased risk in men. ${ }^{15}$

We are not aware of any longitudinal study examining the association between a healthy lifestyle behaviour and the prognosis of neck pain. With this backdrop, this study aimed to investigate if a healthy lifestyle behaviour influences the risk of long-duration troublesome neck pain among men and women with occasional neck pain in a general population. Prognostic factors seems to differ between the general population and the working population, for example, physical activity is associated with the prognosis in workers but not in the general population. ${ }^{6}{ }^{16}$ Therefore, we also intended to assess the same associations restricted to a subsample representing the working population.

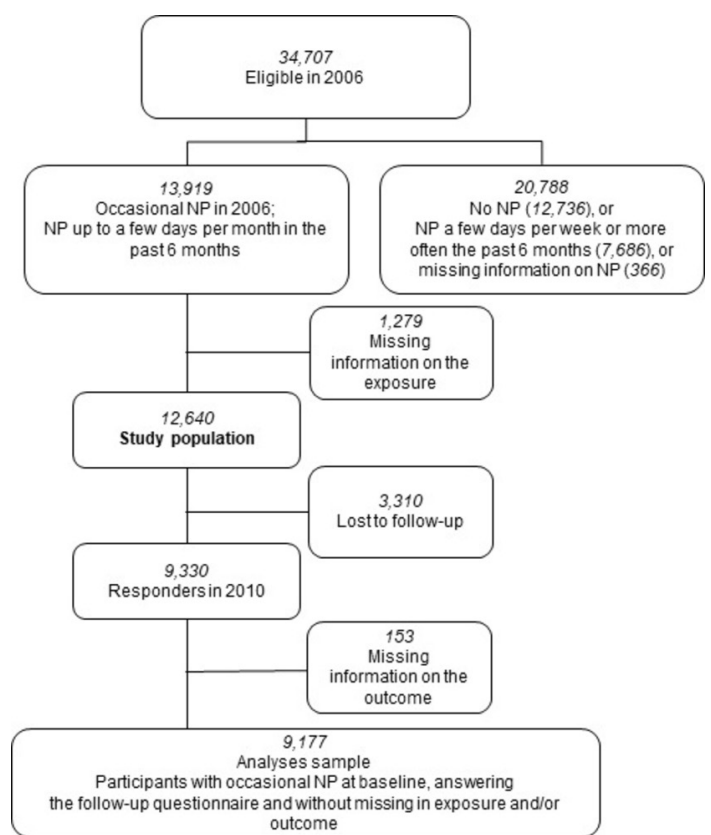

Figure 1 Flow chart describing the inclusion of participants into the study population and the analyses sample. NP; neck pain.

\section{MATERIAL AND METHODS}

\section{Design, source and study population}

This longitudinal cohort study was based on data from the Stockholm Public Health Cohort, a population-based cohort established within the framework of Stockholm County Council health surveys. Participants in the cohort received an extensive baseline questionnaire, including information on demographic and socioeconomic characteristics, physical and psychological health, work related factors and lifestyle. ${ }^{17}$ In 2006, 56634 persons, 18 to 84 years old and randomly selected from the adult population of Stockholm county of about 1.5 million persons, received the baseline questionnaire, which $34707(61 \%)$ answered. Responders received a follow-up questionnaire in 2010, answered by 25167 persons (73\%). Included in our study population were persons reporting occasional neck pain (NP) in 2006, and providing information on the exposure (figure 1). Occasional NP was defined by the answer to the question: 'Have you had any pain in your neck, shoulders or arms in the past 6 months?' Any of the two alternatives: 'Yes, a few days in the past 6 months' or 'Yes, a few days per month' were considered occasional NP. The questions defining neck pain corresponds with the anatomical definition recommended by The Bone and Joint Decade 2000 - 2010 Task Force on Neck Pain and its Associated Disorders: pain in the anatomical region of the neck (also including parts of the shoulder) with or without radiation to the upper limbs, trunk or head. ${ }^{18}$

\section{Exposure}

The exposure 'a healthy lifestyle behaviour' (HLB) was a combination of information regarding four lifestyle factors from the baseline questionnaire (2006) categorised into healthy behaviour/not healthy behaviour according to 
recommendations for a health-enhancing lifestyle made by Swedish authorities and the WHO. ${ }^{19-22}$ Healthy behaviour (HB) for the four lifestyle factors was defined as: nonsmoking; performing leisure physical activity at least $150 \mathrm{~min}$ at moderate intensity or $75 \mathrm{~min}$ at high intensity per week or a combination of these intensities; consuming less than or equal to $168 \mathrm{~g}$ alcohol per week for men and less than or equal to $108 \mathrm{~g}$ alcohol per week for women, and consuming alcohol corresponding to half a bottle of spirits $(35 \mathrm{cl})$ on the same occasion less than once a month, and; consuming more than or equal to a total of four servings of fruit and/or vegetables per day (about $400 \mathrm{~g} /$ day). See the online supplementary file for a description of the questions and how the variables were constructed. HLB was categorised into four categories according to the number of HBs included, none or one HB, two HBs, three HBs and four HBs.

\section{Outcome}

The outcome, long-duration troublesome NP was defined by the response to two questions from the follow-up questionnaire in 2010; (1) 'Have you, during the past 6 months, had pain in your upper back or neck?', and (2) 'Have you, during the past 6 months, had pain in your shoulder or arms?'. Both questions were followed by a second question; 'If yes: Have these problems caused a decreased workability or impairment in other daily activities'. Participants answering 'Yes, a couple of days per week or more often' to any of the two questions and reported that the problems caused decreased workability or impairment in other daily activities were defined as cases. Hence, the outcome incorporated activity limitation due to neck pain suggested to be of importance for the individual and to have societal consequences. $^{7}$

\section{Potential confounding factors}

Potential confounders, available in the 2006 baseline questionnaire, based on literature and on theoretical and clinical relevance were considered for the association between HLB and long-duration troublesome NP (table 1). ${ }^{23-30}$ Most of the questions used to define the potential confounding factors have since 1975 regularly been used in previous Swedish public health surveys, and since 2002 in the Stockholm Public Health Cohort. ${ }^{17}$

\section{Statistics}

A description of the study population was presented for men and women separately, and by categories of the exposure. Generalised linear models with a binomial distribution and a log-link or an identity-link were used to evaluate the association between exposure and outcome. The results were presented as risk ratios (RR) and risk differences (RD) together with the corresponding 95\% CI. To assess confounding we included potential factors into the crude model one by one. If the inclusion changed the estimated RR by $5 \%$ or more the factor was considered a confounder and was included in the final adjusted model. ${ }^{31}$ We used the Wald's test to evaluate potential trends for the association between HLB and long-duration troublesome NP. ${ }^{32}$ All analyses were performed using complete cases, that is, cases with no missing data.

All $\mathrm{p}$ values were two-sided, and the level of the CI was set at $95 \%$ and that of the tests at $5 \%$. Statistical analyses were performed using Stata V.14.2 (StataCorp, College Station, Texas, USA).

\section{Sensitivity analyses}

The same statistical methods were performed using data from a subsample of the study population defined as the 'working population' in order to compare these results with the results from the general population. Since most Swedish employees initiate their retirement at the age of 65 , this subsample included data from participants aged 61 or younger, and currently employed, self-employed or job-applicants at baseline in 2006.

$X^{2}$ tests were used to measure the effect of attrition by comparing the distribution of the exposure categories between non-responders $(\mathrm{n}=3310)$ and responders $(\mathrm{n}=9330)$ in 2010 (figure 1). Moreover, as the questions defining the study population in 2006 and the outcome in 2010 differed some participants may have reported merely shoulder and/or arm pain and not neck pain at baseline and follow-up. Therefore, we also performed the analyses excluding participants only reporting activity limiting pain in shoulder or arms, and not in the upper back or neck in 2010.

\section{Patient and public involvement}

Patients and the public were not involved in the design or planning of the study.

\section{RESULTS}

Baseline characteristics of men and women in the study population are presented in table 2. Of the 12640 participants 58\% were women, about four-fifths were born in Sweden and $11 \%$ were 65 years or older. At baseline in 2006, a larger proportion of women than men had a low risk consumption of alcohol, $71 \%$ and $66 \%$, respectively, and reached the recommended consumption of fruit and vegetables, $24 \%$ and $7 \%$, respectively. About $40 \%$ of men and women reached the recommended levels of leisure time physical activity, and the majority did not smoke, $84 \%$ of the women and $86 \%$ of men. Further, $31 \%$ of the men and $22 \%$ of the women had none or one $\mathrm{HB}$ according to recommendations, and $3 \%$ of the men and $10 \%$ of the women reached the recommendations in all four HBs (table 2).

Ten per cent of the men and $12 \%$ of the women among responders in 2010 stated long-duration troublesome NP, whereas $39 \%$ of the men and $31 \%$ of the women reported no NP. Sex, socioeconomic status (SES) and low back pain were found to be confounders in the analyses of all participants. Compared with participants with none or one HB, participants with three or four HBs at baseline had an adjusted RR and RD of 0.69 (95\% CI 0.59 to 0.81 ) and $-0.04(95 \%$ CI -0.06 to -0.02$)$, respectively. In the analyses stratified by sex the association between the exposure and 
Table 1 Potential confounding factors and corresponding bibliographical references to definition and psychometric properties of the factors

\begin{tabular}{|c|c|c|}
\hline Potential confounder & Measurement & Categorisation in the analyses \\
\hline Sex & Sex at baseline 2006 & Men, women (no other alternatives available) \\
\hline Age & Age at baseline 2006 & $\begin{array}{l}\text { Continuous and in quartiles (18-33, 34-43, } 44-57 \text {, } \\
58-84)\end{array}$ \\
\hline Body mass index & Weight/height ${ }^{2}\left(\mathrm{~kg} / \mathrm{m}^{2}\right)$ & $\begin{array}{l}\text { Normal or low }(<25) \text {, overweight }(25-29.9) \text {, obese } \\
(\geq 30)\end{array}$ \\
\hline Socioeconomic status & $\begin{array}{l}\text { According to the classification from Statistics Sweden. } \\
\text { Based on current occupation and education for the } \\
\text { economically active population, and on previous occupation, } \\
\text { education or the occupation of spouses for the non-active } \\
\text { population }\end{array}$ & $\begin{array}{l}\text { Unskilled/semiskilled worker, skilled worker, } \\
\text { low level non-manual employees, middle level } \\
\text { non-manual employees, high level non-manual } \\
\text { employees/self-employed, self-employed (other } \\
\text { than high level) }\end{array}$ \\
\hline Financial stress & $\begin{array}{l}\text { 'Has it ever happened in the past } 12 \text { months that you have } \\
\text { spent your entire pay check/pension or run out of money and } \\
\text { been forced to borrow from relatives and friends in order to buy } \\
\text { groceries or pay the rent?' }\end{array}$ & No, yes-once, yes-several times \\
\hline Practical support ${ }^{23}$ & $\begin{array}{l}\text { 'Can you obtain help from anyone in the event of illness or } \\
\text { for practical problems? (eg, to borrow small items, help for } \\
\text { repairs, help writing, obtain advice or information or help buying } \\
\text { groceries)' }\end{array}$ & $\begin{array}{l}\text { No-usually not or never, yes-always or for the most } \\
\text { part }\end{array}$ \\
\hline
\end{tabular}

$\begin{array}{ll}\text { Long-term illness } & \begin{array}{l}\text { 'Do you suffer from a long-term illness, health problems } \\ \text { following an accident, disability or other persistent health } \\ \text { problems?' }\end{array} \\ \text { Low back pain } & \begin{array}{l}\text { 'Have you had any pain in your lower back in the past } \\ 6 \text { months?' }\end{array}\end{array}$

No, yes seldom, yes-a couple of days per week or more often

\begin{tabular}{|c|c|c|}
\hline Headache/migraine & $\begin{array}{l}\text { 'Do you have any of the following health problems or } \\
\text { symptoms?' } \\
\text { Headache or migraine (etc...) }\end{array}$ & No, yes-somewhat or severe \\
\hline Rheumatoid arthritis & $\begin{array}{l}\text { 'Have you received any of the following diagnosis by a doctor?' } \\
\text { Rheumatoid arthritis (etc...) }\end{array}$ & No, yes \\
\hline Sleep disturbances & $\begin{array}{l}\text { Hours of sleep a typical night during the workweek. } \\
<7 \text { hours was considered as having sleep disturbances }\end{array}$ & No, yes \\
\hline Working hours* & $\begin{array}{l}\text { How many total hours per week do you spend carrying out paid } \\
\text { work? Do not count work at home or in the household. }\end{array}$ & $>45$ hours, 36 to 45 hours, $<36$ hours \\
\hline Physical workload ${ }^{\star 30}$ & $\begin{array}{l}\text { How much have you moved about or exerted yourself physically } \\
\text { in your work in the past } 12 \text { months? }\end{array}$ & $\begin{array}{l}\text { Sedentary work, light but somewhat mobile work, } \\
\text { moderately heavy or heavy work }\end{array}$ \\
\hline
\end{tabular}

*Factors only considered in the 'working population' (participants 61 years old or younger, and currently employed, self-employed or job-applicants at baseline in 2006).

the outcome was confounded by SES and low back pain. The stratified crude RR and adjusted RR and RD, together with their $95 \% \mathrm{CI}$, are presented in table 3 . A decreased risk for long-duration troublesome NP with increasing adherence to HLB, that is, increased number of HBs at baseline, was found in all analyses (trend test; $\mathrm{p}<0.05$ ).

\section{Sensitivity analyses}

Working population

Seventy-eight per cent of the study population were active in the labour market (working or job-applicants), representing the working population $(\mathrm{n}=7288 ; 2884$ men and 4404 women). In this population, SES met the criteria for a confounder among both men and women, whereas low back pain and personal support confounded the association among men, and financial support the association among women. The adjusted analyses indicated similar results as the analyses of all participants, with a RR of 0.78 (95\% CI 0.56 to 1.08) and a RD of -0.03 (95\% CI -0.05 to 0.002$)$ observed in men with three or four HBs compared with men with none or one $\mathrm{HB}$, and a RR of 0.66 (95\% CI 0.52 to 0.84 ) and a RD of -0.05 (95\% CI -0.08 to -0.02$)$ observed for the same comparison in women. 


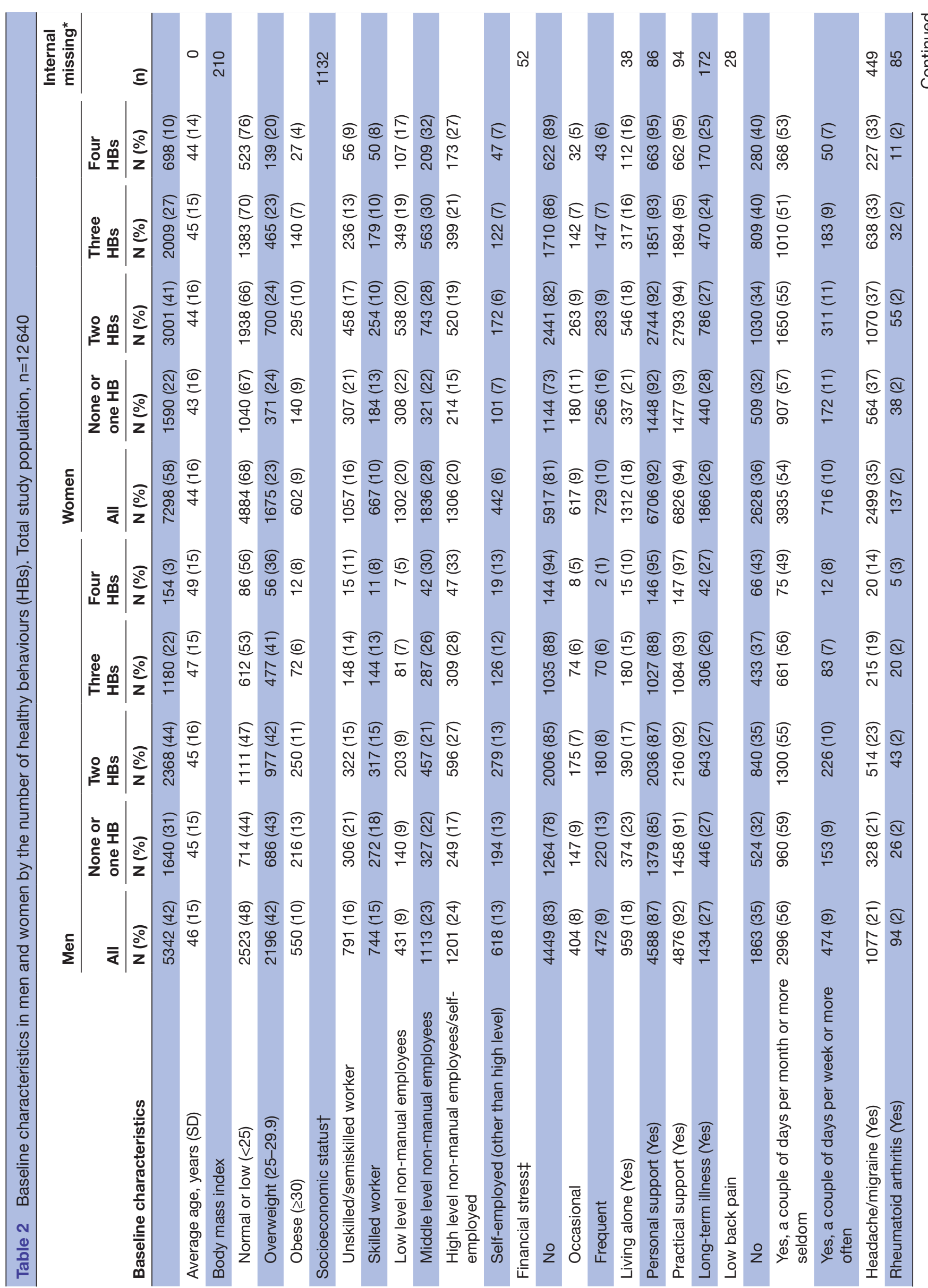




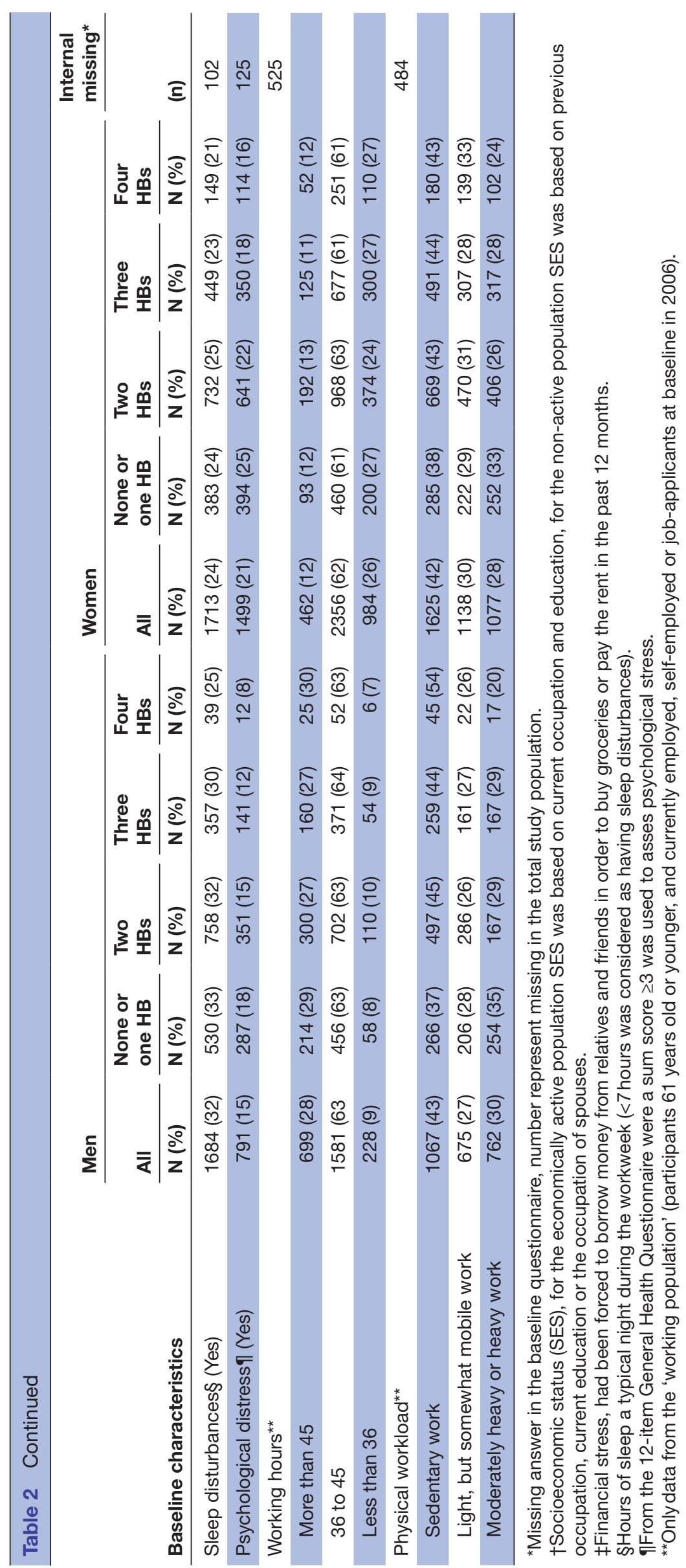



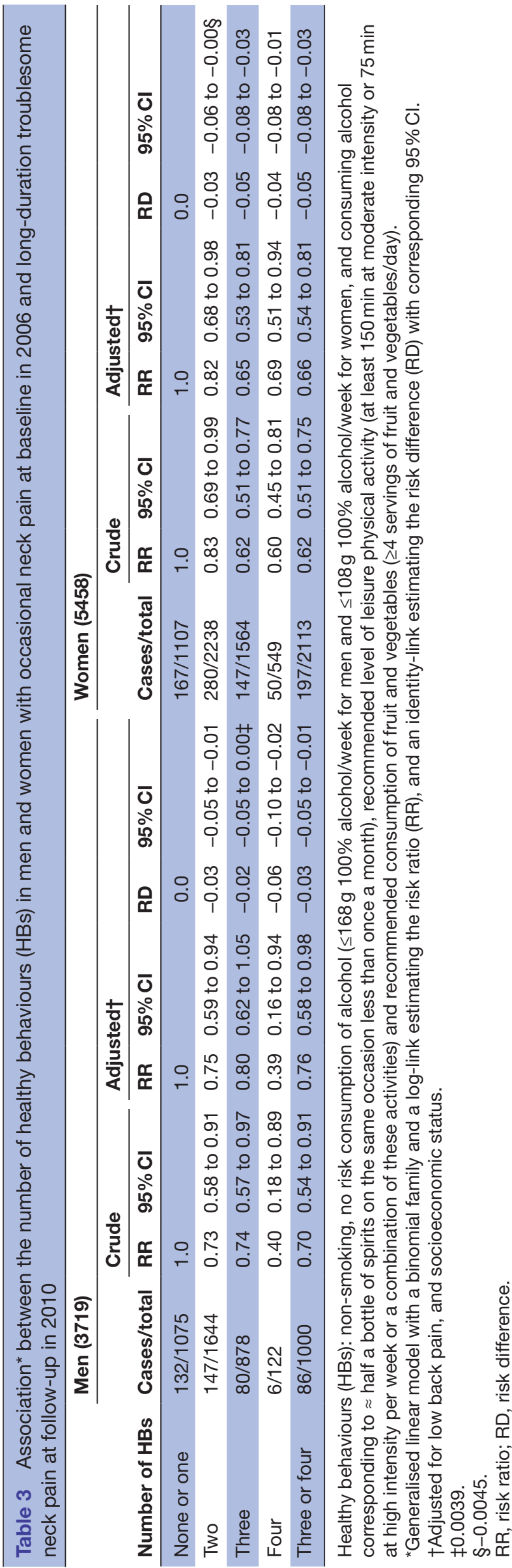

Attrition

The comparison between the 3310 non-responders and the 9330 responders at follow-up indicated a somewhat poorer lifestyle among non-responders. At baseline, $31 \%$ of the non-responders reported none or one HB compared with $24 \%$ of the responders $(p<0.05)$. Furthermore, $21 \%$ of the non-responders reported three HBs and $5 \%$ reported four HBs compared with $27 \%$ and $7 \%$ among the responders $(\mathrm{p}<0.05)$. Excluding participants possibly only affected by shoulder and/or arm pain and not neck pain resulted in almost identical results as in the main analyses, but with non-significant estimates in some categories of HLB in the analyses stratified by sex.

\section{DISCUSSION}

In this longitudinal population-based cohort study involving persons with occasional NP we found that a HLB, that is, adherence to health recommendations (HBs) regarding levels of leisure physical activity, consumption of alcohol, fruit and vegetables and smoking, decreased the risk of long-duration troublesome pain in the neck among men and among women, 4 years later. The results indicated that the protective effect of HLB increased with increasing number of recommendations followed, both in men and in women. Furthermore, our results showed that in comparison to having a 'poor' HLB (none or one HB) at baseline in 2006, having a 'good' HLB (three or four $\mathrm{HBs}$ ) gave an absolute reduction of long-duration troublesome NP 4years later by about three per cent among men and five per cent among women.

Similar results were seen when restricting the analyses to the working population.

We found no other studies evaluating the influence of HLB on the prognosis of neck pain. However, the findings in the current study are in line with a previous study from our group, also based on the Stockholm Public Health Cohort, where HLB was shown to protect against a poor outcome among women with low back pain. Likewise, with an increasing protecting effect with increasing adherence to HLB. ${ }^{15}$ The results indicated a similar, but not significant, effect in men. Hence, in summary it seems as adapting to a healthy lifestyle behaviour is beneficial in order to decrease the risk of a poor outcome both among persons with neck pain and persons with back pain. In another study, again within the Stockholm Public Health Cohort, but including persons free of neck pain and/or back pain in 2006, we found a healthy lifestyle behaviour to decrease the risk of developing long-duration troublesome neck pain among women, and a decreased risk of developing long-duration back pain among men. ${ }^{14}$

The influence of HLB on NP found in the present study may involve different mechanisms, most yet unknown. Moreover, adhering to HLB could indicate an 'overall' healthier lifestyle including other HBs than measured in the present study, thus involving additional mechanisms maybe contributing to our results. 


\section{Strengths and limitations}

The validity of the associations between HLB and longduration troublesome NP is supported by the longitudinal study design, measuring the exposure prior to the outcome and the dose-response relationship found. We consider the large sample size and the comprehensive confounder assessment to be strengths in this study, though residual and unmeasured confounding cannot be ruled out. For example, we had no information about cognitive abilities such as coping strategies, which has been reported to be associated with the prognosis of NP and may also differ across categories of HLB. ${ }^{24}$

The study also has some limitations. Even though most of the questions included in the Stockholm Public Health surveys have been frequently used, and found valid and reliable, some may not be optimal in terms of validity and reliability. ${ }^{17}$ The study is based on self-reported data why information bias is likely to be present, resulting in misclassification of both the exposure and the outcome. For example, the measure of smoking habits only included daily smoking without information on previous smoking habits or the duration of daily smoking. If the effect of smoking on the prognosis NP depends on the duration of daily smoking, which is likely, classifying participants who recently stopped smoking as non-smokers or participants recently started smoking as smokers may have introduced misclassification of the exposure. If so, it most likely would be non-differential and lead to an underestimation of the results. Considering the often fluctuating course of NP, misclassification of the outcome may be present as participants may be irresolute to report 'a couple of days per week' or 'a couple of days per month' when asked to report the duration of neck pain averaged over the past 6 months. Such misclassification is most probably non-differential and may lead to underestimated results. The follow-up time of 4 years are relatively long and there is a possibility that some participants changed their healthy behaviours during that time. We had no intention to measure such changes in the present study, but if some participants changed to another exposure category during follow-up this most likely lead to a dilution of our estimates. In comparison to the other HBs, a relatively small proportion of the participants, particularly men, reached the recommendations for fruit and vegetable consumption. Giving fruit and vegetable consumption the same weight as the other HBs in the exposure may be argued. Nevertheless, we wanted to capture an overall HB exposure. Since consumption of fruit and vegetables is an essential part of a healthy lifestyle as recognised by WHO, and other studies have included it as an important factor to measure HLB, we decided to include it. ${ }^{10} 121321$ Considering a broader definition of dietary habits, also including consumption of carbohydrates, meat and fish is an option. Unfortunately, there were no such data in the questionnaires.

Having NP at baseline in 2006 may have influenced the health behaviours included in the exposure HLB. For example, high NP intensity could have influenced the participants level of physical activity, or consumption of alcohol, that is, reverse causation. Reverse causation may lead to an overestimation of our results. However, as participants in this study only had occasional NP at baseline (ie, NP a few days per month or a few days during the past 6 months) we believe that the risk of reverse causation is low.

Comparing non-responders to responders, the former had a slightly higher prevalence of none or one HB and a slightly lower prevalence of three and four HBs. If nonresponders with none or one $\mathrm{HB}$ also had a higher prevalence of the outcome and non-responders with three or four HBs had a lower prevalence of the outcome than did responders, our results may be underestimated. If contrary, our results may be overestimated.

Interesting and notable in relation to this study is that there is no global consensus on recommendations for weekly risk consumption of alcohol. ${ }^{33}$ Maximum weekly intake of alcohol ranges from $144 \mathrm{~g} / \mathrm{w}$ (Mexico) to $280 \mathrm{~g} / \mathrm{w}$ (Poland) for men, and from $80 \mathrm{~g} / \mathrm{w}$ (Estonia) to $140 \mathrm{~g} / \mathrm{w}$ (Ireland, Poland, France, New Zealand and Spain) for women. However, this inconsistency will not affect the generalisability of our results.

\section{Meaning of the study}

To date it seems evident that HLB decreases the risk and improve the prognosis of several disorders as well as prolong life expectancy. Our results add NP to disorders positively influenced by HLB. Even though our results are fairly modest in absolute terms (RD) they are of importance considering the high prevalence of NP and valuable for healthcare providers in their management of persons with neck pain as well as for employers and policymakers. We encourage studies on implementation of actions to improve healthy lifestyle since there are many positive health effects having a healthy lifestyle.

\section{CONCLUSION}

A healthy lifestyle behaviour appears to decrease the risk of long-duration troublesome neck pain in men and women with occasional neck pain. Furthermore, this protective effect seems to increase with increasing number of healthy lifestyle behaviours. Our findings add to previous research supporting the importance of promoting a healthy lifestyle in primary and secondary prevention of disease and disability, not least for musculoskeletal disorders like neck pain and back pain.

\section{Author affiliations}

${ }^{1}$ Institute of Environmental Medicin, Karolinska Institutet, Stockholm, Sweden ${ }^{2}$ Department of Public Health and Caring Sciences, Uppsala University, Uppsala, Sweden

${ }^{3}$ Department of Health Promotion Science, Sophiahemmet University, Stockholm, Sweden

${ }^{4}$ Naprapathögskolan-Scandinavian College of Naprapathic Manual Medicine, Stockholm, Sweden

Contributors TBo, LHo, OPi, ESk contributed to the conceptualisation and methodology of the study. ESk and JHa provided the data resources.TBo made the 
statistical analyses supported by ESk, LHo and OPi, and wrote the first manuscript version. All authors contributed to the interpretation of the results and critically revised all versions of the manuscript and finally approved the last version.

Funding This study was supported by AFA Insurance, grant number 170095 (ESk, LHo).

Disclaimer The funders had no role in study design, data collection and analysis, decision to publish or preparation of the manuscript.

Competing interests None declared.

Patient consent for publication Not required.

Ethics approval The study was approved by the regional ethic review board at Karolinska Institutet, Stockholm, Sweden (dnr. 2013/497-32). The questionnaires included information about the handling of personal data, and participants accepted the use of their data by answering to the questionnaires (written informed consent).

Provenance and peer review Not commissioned; externally peer reviewed.

Data availability statement Data are available upon reasonable request. Due to ethical restrictions and laws (GDPR) of disclosing personal data, authors have to seek permission to allow us to make the data used in this study available. Data will be available upon request after permission is granted from the Karolinska Institutet's Ethics Review Board in Stockholm. Inquiries for data access should first be sent to eva.skillgate@ki.se, who will then contact the ethics board for permission to openly share the data.

Open access This is an open access article distributed in accordance with the Creative Commons Attribution Non Commercial (CC BY-NC 4.0) license, which permits others to distribute, remix, adapt, build upon this work non-commercially, and license their derivative works on different terms, provided the original work is properly cited, appropriate credit is given, any changes made indicated, and the use is non-commercial. See: http://creativecommons.org/licenses/by-nc/4.0/.

ORCID iD

Tony Bohman http://orcid.org/0000-0001-9507-6101

\section{REFERENCES}

1 Vos T, Allen C, Arora M, et al. Global, regional, and national incidence, prevalence, and years lived with disability for 310 diseases and injuries, 1990-2015: a systematic analysis for the global burden of disease study 2015. The Lancet 2016;388:1545-602.

2 Hoy D, March L, Woolf A, et al. The global burden of neck pain: estimates from the global burden of disease 2010 study. Ann Rheum Dis 2014;73:1309-15.

3 Côté P, van der Velde G, Cassidy JD, et al. The burden and determinants of neck pain in workers: results of the bone and joint decade 2000-2010 Task force on neck pain and its associated disorders. Spine 2008;33:S60-74.

4 Hogg-Johnson S, van der Velde G, Carroll LJ, et al. The burden and determinants of neck pain in the general population: results of the bone and joint decade 2000-2010 Task force on neck pain and its associated disorders. Spine 2008;33:S39-51.

5 Socialförsäkringsrapport. Sjukfrånvarons utveckling 2017 (Social Insurance Report. The Developement of Sick Absence 2017). 2017; Report 2017:13. In Swedish. Available: https://www. forsakringskassan.se/wps/wcm/connect/1596d32b-7ff7-48118215-d90cb9c2f38d/socialforsakringsrapport-2017-13.pdf?MOD= AJPERES\&CVID=

6 Carroll LJ, Hogg-Johnson S, van der Velde G, et al. Course and prognostic factors for neck pain in the general population: results of the bone and joint decade 2000-2010 Task force on neck pain and its associated disorders. Spine 2008;33:S75-82.

7 Carroll LJ, Hurwitz EL, Côté P, et al. Research priorities and methodological implications: the bone and joint decade 20002010 Task force on neck pain and its associated disorders. Spine 2008;33:S214-20.

8 Palmore E. Health practices and illness among the aged. Gerontologist 1970;10:313-6.

9 Li Y, Pan A, Wang DD, et al. Impact of healthy lifestyle factors on life Expectancies in the US population. Circulation 2018;138:345-55.

10 Pronk NP, Lowry M, Kottke TE, et al. The association between optimal lifestyle adherence and short-term incidence of chronic conditions among employees. Popul Health Manag 2010;13:289-95.
11 Chow CK, Jolly S, Rao-Melacini P, et al. Association of diet, exercise, and smoking modification with risk of early cardiovascular events after acute coronary syndromes. Circulation 2010;121:750-8.

12 Ford ES, Bergmann MM, Kröger J, et al. Healthy living is the best revenge: findings from the European prospective investigation into cancer and Nutrition-Potsdam study. Arch Intern Med 2009;169:1355-62.

13 Loef $\mathrm{M}$, Walach $\mathrm{H}$. The combined effects of healthy lifestyle behaviors on all cause mortality: a systematic review and metaanalysis. Prev Med 2012;55:163-70.

14 Skillgate E, Pico-Espinosa OJ, Hallqvist J, et al. Healthy lifestyle behavior and risk of long duration troublesome neck pain or low back pain among men and women: results from the Stockholm public health cohort. Clin Epidemiol 2017;9:491-500.

15 Bohman T, Alfredsson L, Jensen I, et al. Does a healthy lifestyle behaviour influence the prognosis of low back pain among men and women in a general population? a population-based cohort study. BMJ Open 2014;4:e005713.

16 Carroll LJ, Hogg-Johnson S, Côté P, et al. Course and prognostic factors for neck pain in workers: results of the bone and joint decade 2000-2010 Task force on neck pain and its associated disorders. Spine 2008;33:S93-100.

17 Svensson AC, Fredlund P, Laflamme L, et al. Cohort profile: the Stockholm public health cohort. Int J Epidemiol 2013;42:1263-72.

18 Guzman J, Hurwitz EL, Carroll LJ, et al. A new conceptual model of neck pain: linking onset, course, and care: the bone and joint decade 2000-2010 Task force on neck pain and its associated disorders. Spine 2008;33:S14-23.

19 Andreasson S, Allebeck P. Alkohol och Hälsa (alcohol and health). Statens Folkhälsoinstitut (Swedish National Institute of public health) 2005; report no 2005. Available: http://www.riskbruk.se/ WebControls/Upload/Dialogs/Download.aspx?ID=3038

20 World Health Organization (WHO). Global strategy on diet, physica activity and health. physical activity and adults, 2010. Available: https://www.who.int/dietphysicalactivity/factsheet_adults/en/

21 World Health Organization (WHO). Global strategy on diet, physical activity and health. promoting fruit and vegetable consumption around the world, 2010. Available: https://www.who.int/ dietphysicalactivity/fruit/en/

22 Socialstyrelsen (The National Board of Health and Welfare). Nationella riktlinjer för prevention och behandling Vid ohälsosamma levnadsvanor - Stöd för styrning och ledning. (national guidelines for prevention and treatment of unhealthy lifestyle), 2018. Available: https://www.socialstyrelsen.se/regler-och-riktlinjer/nationellariktlinjer/slutliga-riktlinjer/levnadsvanor/

23 McDowell I. Measuring health a guide to rating scales and questionnaires. 3rd edn. Oxford University Press, 2006.

24 Haldeman S, Carroll L, Cassidy JD. Findings from the bone and joint decade 2000 to 2010 Task force on neck pain and its associated disorders. J Occup Environ Med 2010;52:424-7.

25 Kamper SJ, Rebbeck TJ, Maher CG, et al. Course and prognostic factors of whiplash: a systematic review and meta-analysis. Pain 2008;138:617-29.

26 Palmlöf L, Skillgate E, Alfredsson L, et al. Does income matter for troublesome neck pain? a population-based study on risk and prognosis. J Epidemiol Community Health 2012;66:1063-70.

27 Walton DM, Carroll LJ, Kasch H, et al. An overview of systematic reviews on prognostic factors in neck pain: results from the International collaboration on neck pain (icon) project. Open Orthop J 2013;7:494-505.

28 Goldberg DP, Gater R, Sartorius N, et al. The validity of two versions of the GHQ in the who study of mental illness in general health care. Psychol Med 1997;27:191-7.

29 Undén AL, Orth-Gomér K. Development of a social support instrument for use in population surveys. Soc Sci Med 1989;29:1387-92.

30 Leijon O, Wiktorin C, Härenstam A, et al. Validity of a selfadministered questionnaire for assessing physical work loads in a general population. J Occup Environ Med 2002;44:724-35.

31 Rothman KJ, Greenland S, Lash TL. Modern epidemiology. 3rd ed. Philadelphia: Wolters Kluwer Health/Lippincott Williams \& Wilkins, 2008: 261-3.

32 Hosmer DW, Lemeshow S. Applied logistic regression. 2nd ed. Wiley, New York: Chichester, 2000: 11-17.

33 Furtwaengler NAFF, de Visser RO. Lack of international consensus in low-risk drinking guidelines. Drug Alcohol Rev 2013;32:11-18. 